\title{
High resolution pulmonary computed tomography scans quantified by analysis of density distribution: application to asbestosis
}

\author{
Davor Eterović, Željko Dujić, Jadranka Tocilj, Vesna Čapkun
}

\begin{abstract}
A new method for quantitative evaluation for high resolution computed tomography (HRCT) of the lungs was developed by assessment of the distribution of radiological densities within the lung slices. To enable effective reduction of data and improve the sensitivity of detection of abnormalities, the density distributions were analysed by curve fitting through the $\gamma$ variate model. The output of two variables proved most representative: the most frequent density (Hoansfield units; HU) and width of distribution (HU). The method was applied to seven patients with early asbestosis (positive histological finding and International Labour Office (ILO) profusion score up to $0 / 1), 15$ patients with advanced stage of asbestosis (positive histological finding and ILO score above 1/2), and 13 normal controls. All patients with early asbestosis had isolated reduction of diffusing lung capacity to carbon monoxide (DLco), whereas all patients with advanced asbestosis had reduced DLCo and restrictive disease; two of them also had an obstruction pattern. The most frequent densities were significantly greater in the advanced asbestosis group $(-567 \mathrm{HU})$ when compared with both the early asbestosis group $\left(-719 \mathrm{HU} ; p=2 \times 10^{-6}\right)$, and controls $(-799$ HU; $p=0$ ), and they also discriminated significantly between the early asbestosis group and controls $(p=0.0002)$. Significantly stronger linear correlations were established between DLco and the most frequent densities $(r=$ $0 \cdot 86)$ than between DLCo and HRCT score $(r=$ $0 \cdot 57)$ or ILO score $(r=0 \cdot 34)$. It is concluded
\end{abstract}

Department of Nuclear Medicine, Clinical Hospital Split, 58000 Split, Republic of Croatia

D Eterović, V Capkun

Department of Physiology, Zagreb University School of Medicine in Split, 58000 Split, Republic of Croatia

Z Dujić

Division of Pulmonary Medicine, Clinical Hospital Split, 58000 Split, Republic of Croatia

J Tocilj that fitting the curve of the density distribution enables a more objective assessment of HRCT pulmonary scans, especially in the early stage of asbestosis.

\section{(British fournal of Industrial Medicine 1993;50:514-519)}

Lung parenchymal abnormalities on high resolution computed tomography (HRCT) have been described in subjects exposed to asbestos..$^{1-5}$ It was reported that advanced features of the HRCT technique (thin $1-1.5 \mathrm{~mm}$ sections, maximum $x$ ray energy levels, and high resolution reconstruction algorithms) improved its sensitivity in comparison with chest radiographs and conventional computed tomography (CT). ${ }^{3}$ Staples et al found that in asbestos exposed subjects with normal chest radiographs, HRCT can identify a subgroup with decreased lung function. ${ }^{5}$ We have also reported that HRCT can detect early parenchymal changes in subjects exposed to asbestos who had normal chest radiographs and reduced diffusing lung capacity to carbon monoxide (DLCO). ${ }^{6}$ The interpretation of HRCT scans is usually based on a qualitative assessment of changes in morphological characteristics and attenuation by an experienced thoracic radiologist. Qualitative HRCT still lacks data on observer variability similar to the established analysis of chest radiographs classified by the International Labour Offices method (1980).$^{78}$

In tomograms in which the diffuse aspect is featured, as is possible in various interstitial lung diseases, the distribution of radiological densities, $\mu(\mathrm{HU})$, in the particular slice, $f(\mu)$, may show the items that are not transparent on the tomograms themselves. This is so because the subtle variations in the proportion of densities may be more easily seen on the graph, $f(\mu)$, which displays explicitly the number of cells in the successive density intervals. Quantitative analysis of the CT scans with respect to attenuation of an $x$ ray beam by a volume of lung tissue has been used in assessing pulmonary emphysema, ${ }^{910}$ silicosis, ${ }^{11}$ sarcoidosis, ${ }^{12}$ and lung damage related to bleomycin. ${ }^{13}$ The evidence of the small changes, however as within individual follow up, may be hindered by the arti- 
facts in the raw data. Therefore, to improve the sensitivity of detection of abnormalities on HRCT, we suggested the use of the fitted model, instead of the raw $f(\mu)$ data. The method is presented in enough detail to enable straightforward implementation of the algorithm. It is shown that fitting the curve of HRCT density data has definite advantages in early detection of asbestosis.

\section{Subjects and methods}

The study population consisted of seven nonsmoking subjects with early asbestosis, 15 nonsmoking subjects with advanced asbestosis, and 13 control non-smoking subjects. Exposure was predominantly to chrysotile in an asbestos cement factory. Diagnosis of asbestosis was verified by histological examination of lung tissue specimens (with transbronchial biopsy). Early asbestosis was defined by positive histological findings and an ILO score up to $0 / 1$, whereas advanced asbestosis was assumed when positive histological findings and an ILO score above 1/2 were present. Data collected included documented occupational exposure and complete clinical evaluation including physical examination, pulmonary function tests, histological diagnosis of asbestosis, chest radiographs, and HRCT.

Chest radiographs (posteroanterior, lateral) were scored by two thoracic radiologists according to the 1980 ILO classification. ${ }^{14}$ Functional pulmonary testing was performed within one week of HRCT scanning and included static and dynamic spirometry (forced vital capacity (FVC), forced expiratory volume in one second $\mathrm{FEV}_{1}, \mathrm{FEV}_{1} / \mathrm{FVC}$, peak expiratory flow (PEF), maximal expiratory flow at $50 \%$ of expiration (MEF $50 \%$ ); Masterlab from Jaeger, Germany) and single breath diffusion lung capacity (DLCO) measurement. The last was carried out with the patients in an upright seated position (Morgan MK-4, UK) and the arithmetic mean of two acceptable tests for each subject was used. The concentrations of the gas components used were $0.3 \%$ carbon monoxide, $9 \%$ helium, $21 \%$ oxygen and balance nitrogen. The DLCO values were adjusted for haemoglobin. ${ }^{15}$ Reference values for spirometry were from Cotes ${ }^{16}$ and for DLCO, and DLCo/alveolar volume (VA) from Cotes and Hall. ${ }^{17}$ Stress testing was performed on a bicycle ergometer (Jaeger, Germany). Arterial blood gases and $\mathrm{pH}$ were analysed with an ABL-2 blood gas analyser (Radiometer, Denmark).

According to the results of pulmonary function tests the subjects were described to five physiological groups. These groups were defined based on criteria as follows: (1) normal group, FVC $\geqslant 80 \%$ predicted, $\mathrm{FEV}_{1} / \mathrm{FVC} \geqslant 70 \%$, and DLCO $\geqslant 80 \%$ predicted; (2) restrictive group, FVC $<80 \%$ predicted and $\mathrm{FEV}_{1} / \mathrm{FVC} \geqslant 70 \%$; (3) obstructive group, $\mathrm{FEV}_{1} / \mathrm{FVC}<70 \%$; (4) mixed restrictiveobstructive group, FVC $<80 \%$ predicted and $\mathrm{FEV}_{1} / \mathrm{FVC}<70 \%$; and (5) isolated DLCO reduction group, DLCO $<80 \%$ predicted.

The HRCT was performed with a Siemens SOMATOM DRG with scan characteristics: $2 \mathrm{~mm}$ thickness, $7 \mathrm{~s}$ scan acquisition time, 720 projections, $125 \mathrm{kV}, 780 \mathrm{mAs}$, a strong edge enhancement algorithm with the total number of 10 scans in five projections through the thorax. ${ }^{3}$ The standard scan levels used were apical, tracheal bifurcation, paracardial, $3 \mathrm{~cm}$ below the paracardial line, and lung base. The subjects were scanned in a prone and a supine position in each projection at suspended maximal expiration. The HRCT scans were all photographed at three window settings: (1) for the pleura and mediastinum, (2) for the lungs, and (3) for the lungs and pleura. These scans were blindly interpreted by two experienced thoracic radiologists. Probability scores (low, intermediate, and high) used for HRCT scans were according to Aberle et al. ${ }^{3}$

A quantitative analysis of the CT scans was focused on $\mathrm{f}\left(\mu_{\mathrm{i}}\right)$ data from the prone level at $3 \mathrm{~cm}$ below the paracardial line. This was because interstitial asbestosis develops preferentially at the posterior region around the lung base. The raw $\mathrm{f}\left(\mu_{\mathrm{i}}\right)$ curve was $\gamma$ fitted (appendix) to produce the ideal smooth curve, which was identified by the parameters: the most frequent density $\mu_{\max }(\mathrm{HU})$, maximal frequency $f\left(\mu_{\max }\right) \quad(\mathrm{N} / \mathrm{HU})$, the curve width $w$ (HU), and the skewness, s (HU) (fig 1 and appendix).

Values are expressed as mean (SD). Unpaired student's $t$ test for small samples was used to evaluate the differences in various functional and

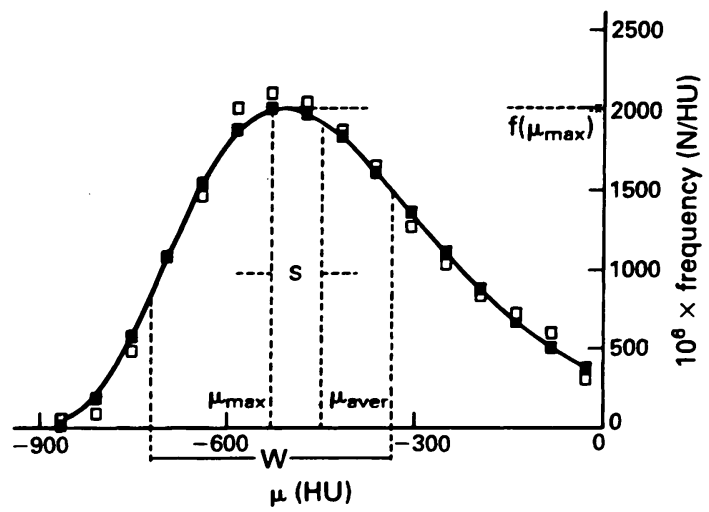

Figure 1 Example of normal lung HRCT density histograms (empty squares) with fitted model (filled squares), featuring its representative parameters: the most frequent density $\mu_{\text {m... }}$, the corresponding frequency, $f\left(\mu_{\text {m.t. }}\right)$, distribution width, $i \dot{ }$, , and distribution skewness, s. 
radiological indices between normal examinees and patients with early or advanced asbestosis. Correlations between DLCO and the most frequent densities, HRCT, or ILO scores were evaluated by linear least squares analysis. A p value $<0.05$ was considered significant.

\section{Results}

Table 1 shows the anthropometric characteristics and lung function, and radiological (chest radiographs and HRCT scans) findings in groups of subjects with early $(n=7)$ or advanced asbestosis $(n=15)$ and 13 non-exposed control subjects. Subjects in group 2 with advanced asbestosis were significantly older $(p=0.015)$ and had longer duration of exposure to asbestos than subjects with early asbestosis (group $1 ; p=0.048$ ). Only six subjects out of 35 (groups 1,2, and 3) were women. The sole functional abnormality in group 1 was a reduction in DLCo. Thirteen subjects out of 15 in group 2 had a Dlco decrement and restrictive disease, one had reduced DLCo and mixed restrictive- obstructive disease, and the other had obstructive disease. Resting $\mathrm{PaO}_{2}$ was significantly decreased in both group 1 and group 2 compared with group 3 ( $p=0.03$ and 0.013 respectively; table 1 ). Exertional hypoxaemia was seen in four subjects in group 1 and in 12 subjects in group 2. The ILO profusion score was $0 / 0(n=4)$ or $0 / 1(n=3)$ in group 1 , whereas in group 3 the scores were $1 / 2$ (n $=4), 2 / 1(n=3), 2 / 2(n=2), 2 / 3(n=4), 3 / 2$ $(n=1), 3 / 3(n=1)$. In group 1 only one subject had circumscribed plaque, whereas in group 213 subjects had circumscribed plaques and two subjects had diffuse pleural thickening. A significantly higher mean HRCT score was found in group 2 compared with group $1(p=0.013)$. For the probability of interstitial fibrosis assessed by HRCT, in group 1 two subjects had low probability whereas four and one had intermediate and high probabilities respectively. In group 2 , four subjects had intermediate and 11 subjects had high HRCT probabilities.

The most frequent densities (for examples see

Table 1 Anthropometric and pulmonary functional and radiological data

\begin{tabular}{|c|c|c|c|c|}
\hline Variables & $\begin{array}{l}\text { Early asbestosis } \\
(n=7) \\
(1)\end{array}$ & $\begin{array}{l}\text { Advanced asbestosis } \\
(n=15) \\
(2)\end{array}$ & $\begin{array}{l}\text { Control subjects } \\
(n=13) \\
\text { (3) }\end{array}$ & $p$ Value \\
\hline \multicolumn{5}{|l|}{$\begin{array}{l}\text { Anthropometric } \\
\text { characteristics: }\end{array}$} \\
\hline $\begin{array}{l}\text { Age (y) } \\
\text { Sex (No men/No women) }\end{array}$ & $34(6)$ & $42(8)$ & $37(7)$ & \multirow{2}{*}{$\begin{array}{l}0.0151 v 2 \\
0.0481 v 2\end{array}$} \\
\hline $\begin{array}{l}\text { Sex (No men/No women) } \\
\text { Abestos exposure (y) }\end{array}$ & $\begin{array}{c}6 / 1 \\
14(9)\end{array}$ & $\begin{array}{l}12 / 3 \\
23(10)\end{array}$ & $11 / 2$ & \\
\hline \multicolumn{5}{|l|}{ Lung function: } \\
\hline FVC (\% predicted) & $90(8)$ & $69(12)$ & $96(6)$ & \multirow{8}{*}{$\begin{array}{l}0.000091 v 2 \text { v } \\
02 v 3 \\
0.000061 v 2 v 2003 \\
0.00082 v 3 \\
0.0341 v 3 \\
0.0022 v 3 \\
0.0281 v 2 \\
0.000052 v 3 \\
0.00381 v 2 \\
02 v 3 \\
02 v 3 \\
0.000021 v 3 \\
0.0062 v 3 \\
0.00021 v 3 \\
0.031 v 2 \\
0.000042 v 3 \\
0.0131 v 3\end{array}$} \\
\hline $\mathrm{FEV}_{1}$ (\% predicted) & $102(13)$ & $78(13)$ & $95(10)$ & \\
\hline $\mathrm{FEV}_{1} / \mathrm{FVC}$ (\% predicted) & $111(12)$ & $114(13)$ & $100(8)$ & \\
\hline PEF (\% predicted) & $90(14)$ & $74(17)$ & $101(11)$ & \\
\hline $\mathrm{MEF}_{50 \%}(\%$ predicted $)$ & $92(13)$ & $72(15)$ & $107(12)$ & \\
\hline DLco (\% predicted) & $69(10)$ & $60(12)$ & $96(9)$ & \\
\hline DLCo/va (\% predicted) & $77(11)$ & $87(11)$ & $98(8)$ & \\
\hline $\mathrm{PaO}_{2}(\mathrm{kPa})$ & $11 \cdot 2(1 \cdot 5)$ & $9 \cdot 4(2 \cdot 3)$ & $12.9(1 \cdot 1)$ & \\
\hline \multicolumn{4}{|l|}{ Chest radiology: } & $0.0131 v 2$ \\
\hline \multicolumn{5}{|l|}{ (No of patients): } \\
\hline $0 / 0$ & 4 & 0 & 13 & \\
\hline $0 / 1$ & 3 & 0 & 0 & \\
\hline $1 / 2$ & 0 & 4 & 0 & \\
\hline $2 / 1$ & 0 & 3 & 0 & \\
\hline $2 / 2$ & 0 & 2 & 0 & \\
\hline $2 / 3$ & 0 & 4 & 0 & \\
\hline $3 / 2$ & 0 & 1 & 0 & \\
\hline $3 / 3$ & 0 & 1 & 0 & \\
\hline
\end{tabular}

Values are mean (SD) unless otherwise indicated. Asbestos exposure = years from the start of exposure; HRCT = high resolution computed tomography score for probability for parenchymal fibrosis $(1=$ low probability; indicates no parenchymal disease; $2=$ intermediate probability; indicates parenchymal disease with possible relation to asbestosis; and $3=$ high probability; indicates parenchymal asbestosis). $\mathrm{p}$ Values obtained by unpaired Student's $t$ test for small samples. 


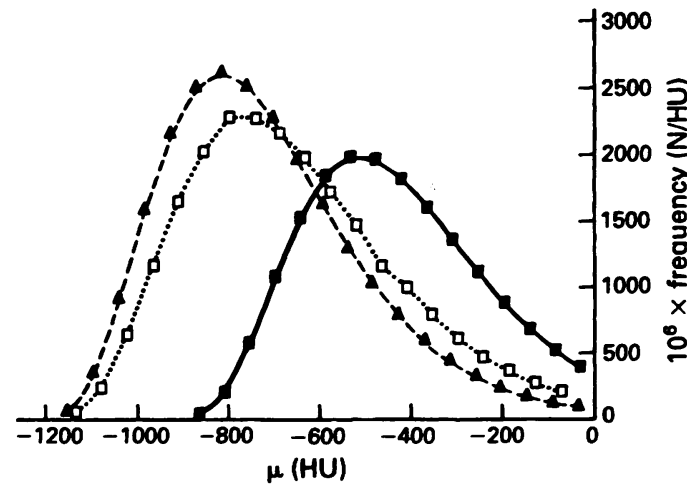

Figure 2 Lung HRCT density histograms (fitted curves) of a normal subject (filled triangles), patient with early asbestosis (empty squares), and patient with advanced asbestosis (filled squares). Note that asbestosis shifts histograms towards greater densities in a stage dependent manner.

fig 2) were significantly greater than the advanced asbestosis group (-567 HU) compared with both the early asbestosis group $(-719 \mathrm{HU}) ; \mathrm{p}=$ $\left.2 \times 10^{-6}\right)$ and controls $(-799 \mathrm{HU} ; \mathrm{p}=0)$ and they discriminated significantly between the early asbestosis group and controls $(p=0.0002)$ (table 2). Significantly stronger linear correlations were established between DLCo and the most frequent densities ( $r=0.87$; fig 3$)$ than between DLCo and HRCT score $(r=0.57)$ or ILO score $(r=0.34)$.

\section{Discussion}

Several recent investigations have suggested that functional abnormalities can give an early diagnosis in asbestosis (and perhaps in other pneumoconiotic lung diseases). ${ }^{18-21}$ We have already reported that decreased FVC and DLCO can be found in subjects with ILO profusion scores below $1 / 1 .^{19}$ We also noticed that a biphasic mid-expiratory flow rate and change in DLCo (initial increase followed by a decrease) in non-smoking subjects may be the earliest functional abnormality indicative of future interstitial asbestosis and that only in the phases when these functional variables returned to normal

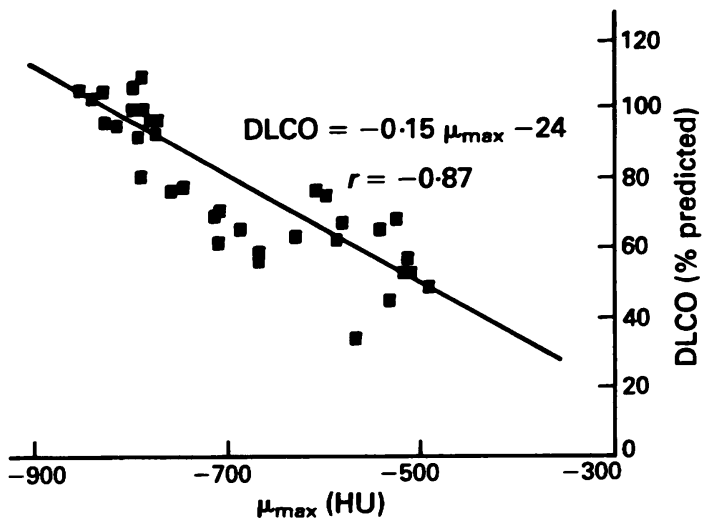

Figure 3 Correlation between diffusing lung capacity for carbon monoxide (DLCO) and the most frequent lung HRCT densities $\left(\mu_{\max }\right)$ in all examinees.

or decreased, did the HRCT become positive in most of these patients, whereas ILO score was still normal. ${ }^{2021}$

Therefore, although HRCT is evidently a more sensitive technique than conventional computed tomography or chest radiography, for an early radiological diagnosis of asbestosis, its qualitative analysis may seem less sensitive than some simple lung function tests: however, the quantitative analysis of HRCT scans is also feasible. The display of number of cells in the successive density intervals, or the histogram of density frequencies proved especially useful. ${ }^{13}$ This is so because such display may show details that are not noticeable by visual inspection of the particular tomogram. The raw density histograms contain, however, a significant noise component that degrades the performances of this analysis, especially regarding reproducibility of measurement, which, in turn, may obscure minor abnormalities or small changes at the patient's follow up. To amplify the performances of utilising HRCT density histograms, we applied the curve fitting technique to the raw density-frequency data.

Such analysis should achieve two main goals:

Table 2 Quantitative parameters of distributions of HRCT densities

\begin{tabular}{lllll}
\hline & $\begin{array}{l}\text { Early asbestosis } \\
(n=7)\end{array}$ & $\begin{array}{l}\text { Advanced asbestosis } \\
(n=15)\end{array}$ & $\begin{array}{l}\text { Control subjects } \\
(n=13)\end{array}$ & $p$ Value \\
Variables & $(1)$ & $(2)$ & $-799(26)$ & $0.00021 v 3$ \\
Most frequent density (HU) & $-719(42)$ & $-567(63)$ & & $02 v 3$ \\
& & & $2 \times 10^{-6} 1 v 2$ \\
Maximal frequency (N/HU) $) 10^{\circ}$ & $2250(461)$ & $1980(495)$ & NS & NS \\
Distribution width (HU) & $360(67)$ & $392(61)$ & $339(49)$ & NS \\
Skewness (\%) & $116(24)$ & $106(21)$ & $94(19)$ & (4) \\
\hline
\end{tabular}

$\mathrm{p}$ Values obtained by unpaired Student's $t$ test for small samples. 
(1) it should attenuate the high frequency statistical artifacts that produce undulation of the ideal unimodal curves; (2) it should effect data reduction to ascribe to the whole curve only the few characteristic parameters. Filtering out the statistical errors enhances reproducibility of analysis, whereas data reduction facilitates comparisons. Local smoothing routines (neighbour averaging) filter out the high frequencies but curve fitting does both smoothing and parametric identification. Quantitatively, in curve fitting, the perfectly smooth curve is dragged through the original curve points. The class of the curve is given by the assumed model and the exact values of the curve variables are determined to produce the best fit of the ideal curve to the raw data. The fitting function is uniquely identified by the parameters of its analytical form. We may further express the descriptive quantities like the curve width, the position, and the height of maximum as the functions of the model parameters. Usually the true model is not exactly known or it is impossible to implement in practice and the approximate concepts are used. The resultant fitting function is fairly accurate in the raw data domain, but it may diverge substantially from the true values if extrapolated outside the original data bounds. In our application the $\gamma$ variate model is only a guess at the true parent distributions, but we do not deal with extrapolations, hence avoiding that possible drawback of the curve fitting concept.

\section{Appendix}

\section{\% VARIATE FUNCTION}

It may be assumed that the actual data comprising the density-frequency pulmogram $f\left(\mu_{i}\right)(i=1, \ldots$, $N)$ are random samples generated from an ideal, parent distribution $f(\mu)$, which is the smooth curve around which the real data are spread. Because $\mathrm{f}\left(\mu_{\mathrm{i}}\right)$ appears as a unimodal, left skewed curve (fig 1 ), it should be described adequately. A versatile model having these features is the \% variate function, well known in statistics, physics, and indicator-dilution curves. ${ }^{22}$ In this model $f(\mu)$ appears as:

$\mathrm{f}(\mu)=\mathrm{c} \cdot\left(\mu-\mu_{\text {on }}\right)^{\mathrm{a}} \cdot \exp \left(-\mathrm{b} \cdot\left(\mu-\mu_{\text {on }}\right)\right)($ A 1$)$ where $\mu_{o n}$ is the curve onset $\left(\mu \geqslant \mu_{o n}\right)$, after which the curve exhibits the single upslope, reaches its maximum, and decays monotonically to zero; $\mathrm{c}$ is the scale factor, and $a$ and $b$ are positive parameters determining the exact shape of the curve. The ideal curve onset $\mu_{o n}$ may be chosen to coincide with the onset of the raw data, whereas the set $a, b$, and $c$ can be determined by the method of least-squares (see next section). Once $\mu_{\mathrm{on}}, \mathrm{a}, \mathrm{b}$, and c are known, we may proceed to calculate the position of the curve maximum $\mu_{\max }$, maximal curve value $\mathrm{f}\left(\mu_{\max }\right)$, and the curve width, $w$, as follows: The root of equation $(d / d \mu) f(\mu)=0$ is

$$
\mu_{\max }=\mu_{\mathrm{on}}+\mathrm{a} / \mathrm{b}
$$

Inserting (A 2) in (A 1) gives:

$$
f\left(\mu_{\max }\right)=c \cdot(a / b)^{a} \cdot \exp (-a)
$$

The curve width, $w$, may be defined as the distance between the two points of inflection, which are the roots of equation $\left(d^{2} / d \mu^{2}\right) f(\mu)=0$. Hence:

$$
\mathrm{w}=2 \cdot \sqrt{\mathrm{a} / \mathrm{b}}
$$

A useful concept may also be the skewness, s, defined here as the difference between the maximal, or most probable density $\mu_{\max }$, given by (A 2), and the average density, $\mu_{\text {ave, defined }}$ below-that is:

$$
\begin{gathered}
s=\mu_{\text {max }}-\mu_{\text {ave }} \\
\mu_{\text {ave }}=\sum_{1}^{N} \mu_{i} \cdot f_{i}\left(\mu_{i}\right)
\end{gathered}
$$

It should be noted that, in unimodal curves, $s<0$ $\left(\mu_{\max }<\mu_{\text {ave }}\right)$ obtains in case of the left skewed curve and vice versa.

\section{LEAST SQUARES FIT OF THE $\gamma$ VARIATE FUNCTION}

The mathematical statement of the best fit to $N$ data points $f\left(\mu_{i}\right)$ is that among all possible sets of parameters of the model function $f(\mu ; a, b, c \ldots)$ we should find the one that produces the minimal sum of the squared deviations of the original curve points $f\left(\mu_{i}\right)$ from the corresponding points of the fitting curve $f\left(\mu_{i} ; a, b, c \ldots\right)$. In other words "the best" set $a, b, c \ldots$ is the minimum of the function:

$$
\left.X^{2}(a, b, c \ldots)=\sum_{1}^{N}\left(f\left(\mu_{i}\right)-f\left(\mu_{i}\right) ; a, b, c \ldots\right)\right)^{2}
$$

The equivalent formulation is that $a, b, c \ldots$ are the roots of the set of simultaneous equations:

$$
\mathrm{dX}^{2} / \mathrm{da}=0, \mathrm{dX}^{2} / \mathrm{db}=0, \mathrm{dX}^{2} / \mathrm{dc}=0, \ldots .
$$

Solving this set is not always trivial but is simple if equations are linear in $a, b, c \ldots$ In the case of the $\gamma$ variate model function of equation A 1 it is impossible to obtain the linear set directly. Therefore it is numerically opportune to subject to the leastsquares demand $\ln f(\mu)$, rather than the function $f$ $(\mu)$ itself. Upon doing the solutions for the parameters $a, b$, and c are readily obtained.

$$
\begin{aligned}
b=\frac{\left(s_{5} \cdot s_{8}-s_{4} \cdot s_{7}\right) \cdot\left(s_{1} \cdot s_{3}-N \cdot s_{5}\right)-}{\left(s_{2} \cdot s_{4}-s_{5}^{2}\right) \cdot\left(s_{1} \cdot s_{3}-N \cdot s_{5}\right)+} & \frac{\left(s_{3} \cdot s_{7}-s_{5} \cdot s_{6}\right) \cdot\left(s_{3} \cdot s_{5}-s_{1} \cdot s_{4}\right)}{\left(s_{2} \cdot s_{3}-s_{1} \cdot s_{5}\right) \cdot\left(s_{3} \cdot s_{5}-s_{1} \cdot s_{4}\right)}
\end{aligned}
$$




$$
\begin{gathered}
c=\exp \left(\frac{b \cdot\left(s_{1} \cdot s_{5}-s_{2} \cdot s_{3}\right)+\left(s_{3} \cdot s_{7}-s_{5} \cdot s_{6}\right)}{s_{1} \cdot s_{3}-N \cdot s_{5}}\right) \\
a=\frac{s_{8}-s_{5} \cdot b-s_{3} \cdot c}{s_{4}} \quad \text { (A 8) }
\end{gathered}
$$

The definitions of abbreviations $s_{1}, \ldots, s_{8}$ follow:

$$
\begin{aligned}
\mathrm{s}_{1} & =\sum_{1}^{N} \mu_{\mathrm{it}} \quad \mathrm{s}_{2}=\sum_{1}^{\mathrm{N}} \mu_{\mathrm{it} 2} \quad \mathrm{~s}_{3}=\sum_{1}^{\mathrm{N}} \ln \mu_{\mathrm{it}} \\
\mathrm{s}_{4} & =\sum_{1}^{\mathrm{N}} \ln ^{2} \mu_{\mathrm{it}} \quad \mathrm{s}_{5}=\sum_{1}^{\mathrm{N}} \mu_{\mathrm{it}} \ln \mu_{\mathrm{it}} \quad \mathrm{s}_{6}=\sum_{1}^{\mathrm{N}} \ln \mathrm{f}\left(\mu_{\mathrm{it}}\right) \\
\mathrm{s}_{7} & =\sum_{1}^{\mathrm{N}} \mu_{\mathrm{it}} \ln \mathrm{f}\left(\mu_{\mathrm{it}}\right) \quad \mathrm{s}_{8}=\sum_{1}^{\mathrm{N}} \ln \mu_{\mathrm{it}} \cdot \ln \mathrm{f}\left(\mu_{\mathrm{it}}\right) \\
\mu_{\mathrm{it}}=\mu_{\mathrm{i}}-\mu_{\mathrm{on}} &
\end{aligned}
$$

Because $\mu_{\text {on }}$ is easily recognised as the curve onset, the equation A 8 expresses the fit parameters of the $\gamma$ variate model of equation A 1 as functions of abscissas and ordinates of the original curve, which, in turn, are the direct observables.

Requests for reprints to: Davor Eterovic, Department of Nuclear Medicine, Clinical Hospital Split, 58000 Split, Republic of Croatia.

1 Yoshimira $\mathrm{H}$, Hatakeyama $\mathrm{M}$, Otsuji $\mathrm{H}$, et al. Pulmonary asbestosis: CT study of subpleural curvilinear shadow. Radiology 1986;158:653-8.

2 Friedman AC, Fiel SB, Fisher MS, Radecki PD, Lev-Toaff AS, Caroline DF. Asbestos-related pleural disease and asbestosis: a comparison of CT and chest radiography. American fournal of Roentgenology, Radium Therapy, and Nuclear Medicine 1988;150:269-75.

3 Aberle DR, Gamsu G, Ray CS. High-resolution CT of benign asbestosis-related diseases: clinical and radiographic correlation. American fournal of Roentgenology, Radium Therapy, and Nuclear Medicine 1988;151:883-91.

4 Aberle DR, Gamsu, G, Ray CS, Feuerstein IM. Asbestosrelated pleural and parenchymal fibrosis: detection with high-resolution CT. Radiology 1988;166:729-34.

5 Staples CA, Gamsu G, Ray CS, Webb WR. High resolution computed tomography and lung function in asbestosexposed workers with normal chest radiographs. $\mathrm{Am}$ Rev Respir Dis 1989;139:1502-8.

6 Boschi S, Vitezica Z, Dujic Z, Tocilj J. The importance of high-resolution CT in the early diagnosis of asbestos-related lung parenchymal disease. Radiol Iugoslav 1990;24:47-50.

7 Reger RB, Amandus HE, Morgan WKC. On the diagnosis of coal workers' pneumoconioses: Anglo-American disharmony. Am Rev Respir Dis 1973;108:1186-91.

8 Amandus HE, Pendergrass EP, Dennis JN, Morgan WKC. Pneumoconioses: inter-reader variability in the classification of the type of small opacities in the chest roentgenograms. American fournal of Roentgenology, Radium Therapy, and Nuclear Medicine 1974;122:740-3.

9 Sanders C, Nath PH, Bailey WD. Detection of emphysema with computed tomography: correlation with pulmonary function tests and chest radiography. Invest Radiol 1988; 23:262-6.

10 Mueller NL, Staples CA, Miller RR, Abboud RT. An objective method to quantitate emphysema using computed tomography. Chest 1988;94:782-7.

11 Rienmuller R, Schatzl M, Kalender W, Krombach F, Fiehl E. Quantitative CT-untersuchungen der lunge am tierexperimentellen model der silikose. Fortschr Roentgenstr 1988;148:347-86.

12 Gilman MJ, Laurens RG, Somogyi JW, Honig EG. CT attenuation values of lung density in sarcoidosis. 7 Comput Assist Tomogr 1983;7:407-10.

13 Bellamy EA, Nicolas D, Husband JE. Quantitative assessment of lung damage due to bleomycin using computed tomography. $\mathrm{Br}$ F Radiol 1987;60:1205-9.

14 International Labour Office. Guidelines for the use of ILO international classificiation of radiographs of pneumoconioses. Geneva: ILO, 1980. (Occupational Safety and Health Series No 22 (Rev).)

15 Cotes JE, Dabbs JM, Elwood PC, Hall AM, McDonald A, Saunders MJ. Iron deficiency anemia: its effect on transfer factor for the lung (diffusing capacity), ventilation, and cardiac frequency during sub-maximal exercise. Clin $S_{c i}$ $1972 ; 42: 325-35$

16 Cotes JE. Lung function at different stages of life, including reference values. In: Cotes JE, ed. Lung function. 3rd ed. Oxford: Blackwell Scientific Publications, 1975:340-95.

17 Cotes JE, Hall AM. The transfer factor for the lung; normal values in adults. In: Arcangeli P, ed. Normal values for respiratory function in man. Torino: Panminerva Medica, 1970:327-43.

18 Rosenstock L, Barnhart S, Heyer NJ, et al. The relation among pulmonary function, chest roentgenographic abnormalities, and smoking status in an asbestos-exposed cohort. Am Rev Respir Dis 1988;138:272-7.

19 Tocilj J, Dujic Z, Boschi S, Saric M. Correlation of radiological and functional findings in workers exposed to chrysotile asbestos. Med Lav 1990;81:373-81.

20 Dujić Z, Tocilj J, Saric M. Early detection of interstitial lung disease in asbestos exposed non-smoking workers by mid expiratory flow rate and high resolution computed tomography. $\mathrm{Br} \mathcal{F}$ Ind Med 1991;48:663-4.

21 Dujić Z, Tocilj J, Boschi S, Saric M, Eterović D. Biphasic lung diffusing capacity: asbestos induced changes in lung function. Br f Ind Med 1992;49:260-7.

22 Thompson HK Jr, Starmer CF, Whalen RE, McIntosh HD. Indicator transit time considered as a gamma variate. Circ Res 1964;14:503-15.

Accepted 27 July 1992 